\title{
Medical students' choices of specialty in The Gambia: the need for career counseling
}

\author{
Mustapha Bittaye ${ }^{1}$, Akin-Tunde Ademola Odukogbe ${ }^{2^{*}}$, Ousman Nyan ${ }^{3}$, Bintou Jallow ${ }^{4}$ \\ and Akinyinka O Omigbodun ${ }^{2}$
}

\begin{abstract}
Background: Understanding preferences for specialties by medical students and the factors driving choices assists policy makers in ensuring optimal spread of personnel across disciplines.

Methods: This cross-sectional survey using self-administered structured questionnaires was conducted on consenting students of the first medical school in The Gambia, established in 1999. Data collection was in June/July 2011. Questions were on sociodemographic characteristics of students, their parents, factors related to career preferences and opinions about counseling services. Data were analysed using JMP 8.0 software.

Results: Respondents were $52.4 \%$ of 202 eligible students. Mean age was $24.1 \pm 5.0$ years. Females constituted 54.7\%. Muslims were $72.7 \%$ while Gambians formed $77.0 \%$. Commonest specialties chosen by females were Obstetrics/Gynaecology, Paediatrics and Surgery in that order, while males preferred Internal Medicine, Surgery and Obstetrics/Gynaecology. Commonest factors influencing choices by females were 'focus on urgent care' (65.5\%) and 'intellectual content of specialty' (56.9\%). For males, these were 'intellectual content of specialty' (60.4\%) and 'focus on urgent care' / 'individual's competence' (50.0\% each). More females (30.0\%) than males (23.0\%) had ever received career counseling, but all students desired it.
\end{abstract}

Conclusions: Significant gender differences exist in specialty choices and factors influencing these choices amongst these students. All want career counseling.

Keywords: Medical students, Specialties, Choices, Careers

\section{Background}

Medical education necessitates students studying a wide scope of medical specialties. In recent years, there is a deeper appreciation of career preference in medicine affecting student learning and academic performance. During preclinical and clinical experiences, medical students construct their professional identity through a process of medical socialization [1]. Within this process, they are focused on acquisition of new knowledge and skills, but they also interact with other medical students, health professionals and patients. Through such interactions, students construct their professional identity grounded in principles of the biomedical model [2].

\footnotetext{
* Correspondence: akin_tundeodukogbe@yahoo.com

${ }^{2}$ Department of Obstetrics and Gynaecology, College of Medicine, University of Ibadan, Ibadan, Nigeria

Full list of author information is available at the end of the article
}

Cultural and societal values also influence future physicians, particularly through student's interactions with family, friends, and physicians [3]. The process of resolving conflicting views from societal constructs and self-realizations shape students' views on the types of specialists they want to become. However, not only medical school entrants [4], but even medical school applicants, often have strong preferences for or against some medical careers [5-8].

A lot of researchers have concentrated on the personal characteristics of individuals choosing particular careers $[9,10]$, on background factors in childhood influencing career preferences $[11,12]$, and on associations with particular personality types [13]. Other studies have highlighted the careers of specific groups, such as women doctors [14], attitudes toward specific specialties, such as Psychiatry [15] and Anaesthesia [16,17] and on the basic statistics necessary for workforce planning [18].

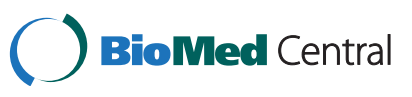

(c) 2012 Bittaye et al.; licensee BioMed Central Ltd. This is an Open Access article distributed under the terms of the Creative Commons Attribution License (http://creativecommons.org/licenses/by/2.0), which permits unrestricted use, distribution, and reproduction in any medium, provided the original work is properly cited. 
Careers differ in their demands, requiring different amounts of intellectual ability, manual skill, long-term commitment, or willingness to work in particular environments [14], and can each be better suited to particular personalities [13], aptitudes, and physical dispositions. Individuals also differ, having different aptitudes, interests and abilities.

Career choice therefore involves people considering the entire range of careers and then circumscribing those which they regard as broadly acceptable, making their eventual choices within that subset [19].

An important practical point highlighted by studies is that choices tend to be negative, meaning that careers are rejected because they do not have attributes which are consonant with the person making the choice, rather than being positively chosen for their special suitability to the person making the choice [19].

Once circumscription has taken place, a number of possible careers still remain. The second stage of choice is compromise. Because of various practical constraints, certain careers are restricted in the number of people they can accommodate or they are unsuitable in other terms, such as their geographical location or the remuneration they can provide. The eventual career chosen is one that 'satisfies' [20], being realistically good, though not optimal. The applications of these theories to medical careers are self-evident and describe many of the problems facing medical students and junior doctors.

Many researchers have demonstrated that career preferences at the time of entering medical school may be a significant predictor of students' eventual careers and that many students end up in careers that are closely related to their choice of specialty at the beginning of medical school. Thus it is very important to define the factors that affect career specialty in the early years of medical school $[7,8]$. Career counselling would identify the students' inclination early and guide them to careers most suitable for them. This will enable medical students find careers that are appropriate for them sooner rather than later [19]. Many doctors devote too much time in their initial postgraduate years toward trying to enter a specialty for which they are either not suited or are insufficiently endowed with the attributes required [21]. This is exemplified by the findings of a study which revealed that, eleven years afterward, only $65 \%$ of doctors ended up in the specialty of their first choice as preregistration house officers [21].

Unavoidable limitations in the breadth of medical school curricula mean that there are some specialties that undergraduates never experience. Only a few medical schools in developing countries have introduced career counseling services for students which give them the opportunity to experiment and explore during elective postings, along the lines of the model offered by the
Career Advisory Service of the American Association of Medical Colleges [19]. However, no studies to explore the choice of careers have been undertaken in the medical school in The Gambia.

The objectives of this study were to determine the career preferences, the factors influencing these choices and the need for career counselling in medical students attending the School of Medicine and Allied Health Sciences, University of The Gambia.

\section{Methods}

\section{Study population}

The University of The Gambia (UTG) medical school, located in the capital city - Banjul, was established in 1999 and has graduated three batches of doctors. It has seven (7) classes. The first year (pre-medical) class covers General Sciences. The pre-clinical class introduces the basic biomedical sciences in a modular format. The clinical class covers clinical clerkships, in which the clinical specialties of Surgery, Internal Medicine, Paediatrics and Obstetrics and Gynaecology are introduced along with selected subspecialties such as Radiology, Anesthesia, Dermatology, Ophthalmology, Psychiatry, and Ear, Nose and Throat. During the clinical years three professional examinations are taken and there is an option of having one elective month. The medical school uses Royal Victoria Teaching Hospital for clinical postings.

\section{Study design}

We did a cross-sectional survey with the study population consisting of all the 202 students in the school. One of the investigators (BJ) gave questionnaires to all class presidents for distribution to all class members. After reading and signing the written consent, participants self administered a structured questionnaire to determine their sociodemographic characteristics, choices of specialty, factors influencing these choices and their opinions on the need for establishment of career counseling services. The occupations of their parents were classified according to the U.S.A 2010 Standard Occupation Classification [22]. In The Gambia, customarily the father is responsible for virtually all household expenses while the mother attends to other needs. Thus we considered the father's occupation having more influence on the school a child attends. Female education is also still generally low, hence the mother's educational level will impart greatly on the development of the child and the economic status of the family.

\section{Ethical approval}

This was granted by the Joint Research and Publication Committee of the School of Medicine and Allied Health Sciences, University of The Gambia. 


\section{Statistical analysis}

Data were analyzed by JMP 8.0 software. The general approach used was to compare the responses of the male to those of the female students. For these analyses, we examined the following basic predictor variables: demographic factors, choice of specialty and factors that influence choice of specialty and opinion on the need for establishment of career counseling services. Results of continuous variables were expressed as mean \pm standard deviation. Statistical analysis was done, using the $\chi 2$-test for all categorized data. Where the chi-square test was not applicable, an appropriate nonparametric test was used. Using nominal logistic regression, we investigated gender differences in the factors likely to contribute or not contribute to career selection among the students. Odds ratios and $95 \%$ confidence intervals were calculated. $\mathrm{P}$ values less than 0.05 were considered statistically significant.

\section{Results}

\section{Socio-demographic characteristics of study population}

The response rate was $52.4 \%, 106$ students returning the completed questionnaire out of 202. Over half, (53.4\%) of the total student population were females. The mean age $( \pm \mathrm{SD})$ of the respondents was 24.1 ( \pm 5.0$)$ years. Only $27.3 \%$ of participants were Christians and the rest were Muslims. The mean age of the fathers of respondents was $58.5( \pm 8.7)$ years and of their mothers was $49.2( \pm 9.3)$ years. The socio-demographic characteristics of the students by gender are described (Table 1). Regarding the response rate and gender, a slight difference between the females (54.7\%) as compared to the males $(45.3 \%)$ was noted, but this was not statistically significant. The female students in the pre-clinical level accounted for more than half of the participants while the male students were predominant among respondents in the clinical classes, with an overall statistically significant difference between the genders at both levels $(\mathrm{p}=0.02)$.

Gambians accounted for more than two-thirds (77.0\%) of the subjects. Nearly $4 \%$ of the students had a physician father. Regarding the educational attainment of the mothers of the students, mothers of the females were significantly more educated than the mothers of male students $(p=0.0217)$. Prior to being admitted into the Medical School, more females (66.7\%) attended private schools than the males (33.3\%), a statistically significant difference $(\mathrm{p}=0.0077)$.

\section{Specialty choices}

The five most common specialties considered by both sexes were Surgery, Obstetrics and Gynaecology, Internal Medicine, Paediatrics and Public Health. If students were allowed three choices, 66 (62.3\%) chose Surgery, 65
(61.3\%) chose Obstetrics and Gynaecology and 63 (59.4\%) chose Internal Medicine amongst both sexes. The most common specialties considered by female students were Obstetrics and Gynaecology, Pediatrics and Surgery respectively while the males considered Internal Medicine, Surgery and Obstetrics and Gynaecology.

But if only those who chose the subjects as a first choice were examined it was found that $36.2 \%$ of females chose Obstetrics and Gynaecology, 21.4\% chose Surgery, 20.7\% chose Paediatrics and 10.3\% chose Internal Medicine while $35.4 \%$ of males each chose Surgery and Internal Medicine and $8.3 \%$ chose Public Health. Only 6.3\% of males chose Obstetrics and Gynaecology. More than $81.0 \%$ of males at least considered Internal Medicine compared to $41.4 \%$ of females. Table 2 shows the different proportions of the choices made.

The students showed little interest in the other subjects including Family Medicine. Only one female chose Anesthesia as a first choice and no male at all did so. More than one-third (35.0\%) of males chose Internal Medicine as first choice as opposed to $10.3 \%$ of females. No female chose Psychiatry as a first choice and only 2 (3.4\%) females chose it as second or third choice while $4.2 \%$ of males chose it as a first choice. Overall $8.3 \%$ of males chose it as one of their choices. No male or female chose ENT in any of their three allowed choices.

Family Medicine was considered by $6.9 \%$ of females and chosen by $1(2.1 \%)$ male as a first choice. No male or female chose Orthopedics as a first choice.

\section{Factors influencing career selection}

The most important factor regarded as being strongly contributory to the choice of specialty among female respondents was 'focus on urgent care' (65.5\%), followed by 'the intellectual content of the specialty' (56.9\%) and 'interest in research' (53.5\%). The most important factor that strongly influenced choice of specialty by males was 'intellectual content of the specialty' (60.4\%) followed by 'focus on urgent care' / 'the individual competencies of the student' (50.0\% each) and 'lack of specialist in that area' / 'interest in research' (45.8\% each).

Table 3 shows the details of the factors affecting the choices of specialty by male and female medical students. There was a significant difference between the genders in some of the factors that they considered significant in influencing their choice of speciality. While $41.7 \%$ (95\% confidence interval, CI: $31.75-51.65$ ) of the males stated that 'duration of residency programme' would influence their choice, only $22.4 \%$ (95\% CI: 13.67 - 31.13) of the females considered this to be a contributory factor $(p=0.0050)$. Male respondents attached more importance to mentor emulation than females when choosing their careers $(p=0.0383)$. 'Lack of specialists in that area' was regarded as contributing to speciality 
Table 1 Socio-demographic characteristics of respondents

\begin{tabular}{|c|c|c|c|c|c|c|c|}
\hline & \multicolumn{2}{|c|}{ Total } & \multicolumn{2}{|c|}{ Female } & \multicolumn{2}{|c|}{ Male } & \multirow[t]{2}{*}{ P-value } \\
\hline & $\mathrm{N}$ & $\%$ & $\mathrm{~N}$ & $\%$ & $\mathrm{~N}$ & $\%$ & \\
\hline Level & 106 & & 58 & 54.7 & 48 & 45.3 & \\
\hline First year & 13 & 12.3 & 9 & 69.2 & 4 & 30.8 & 0.0200 \\
\hline Second year & 30 & 28.3 & 21 & 70.0 & 9 & 30.0 & \\
\hline Third year & 8 & 7.6 & 3 & 37.5 & 5 & 62.5 & \\
\hline Fourth year & 24 & 22.6 & 12 & 50.0 & 12 & 50.0 & \\
\hline Fifth year & 13 & 12.3 & 5 & 38.5 & 8 & 61.5 & \\
\hline Sixth year & 6 & 5.7 & 4 & 66.7 & 2 & 33.3 & \\
\hline Seventh year & 12 & 11.3 & 4 & 33.3 & 8 & 66.7 & \\
\hline \multicolumn{8}{|l|}{ Nationality } \\
\hline Gambians & 77 & 72.6 & 44 & 57.1 & 33 & 42.9 & 0.4136 \\
\hline Others & 29 & 27.4 & 14 & 48.3 & 15 & 51.7 & \\
\hline \multicolumn{8}{|l|}{ High school attended } \\
\hline Public & 49 & 46.2 & 20 & 40.8 & 29 & 59.2 & 0.0077 \\
\hline Private & 57 & 53.8 & 38 & 66.7 & 19 & 33.3 & \\
\hline \multicolumn{8}{|l|}{ Father's occupation } \\
\hline Management, professional, related occupation & 64 & 60.4 & 38 & 59.4 & 26 & 40.6 & 0.2539 \\
\hline Service occupation & 7 & 6.6 & 5 & 71.4 & 2 & 28.6 & \\
\hline Sales and office occupation & 4 & 3.8 & 2 & 50.0 & 2 & 50.0 & \\
\hline Natural resources, construction \& maintenance & 20 & 18.9 & 6 & 30.0 & 14 & 70.0 & \\
\hline Production, transportation \& material moving & 4 & 3.8 & 2 & 50.0 & 2 & 50.0 & \\
\hline Retired & 7 & 6.6 & 5 & 71.4 & 2 & 28.6 & \\
\hline \multicolumn{8}{|l|}{ Mother's educational level } \\
\hline Non-formal & 42 & 39.6 & 16 & 38.1 & 26 & 61.9 & 0.0217 \\
\hline Less than high school & 12 & 11.3 & 10 & 83.3 & 2 & 16.7 & \\
\hline High school & 19 & 17.9 & 12 & 63.2 & 7 & 36.8 & \\
\hline More than high school & 33 & 31.1 & 20 & 60.6 & 13 & 39.4 & \\
\hline \multicolumn{8}{|l|}{ University payment system } \\
\hline Parents & 15 & 14.1 & 8 & 53.3 & 7 & 46.7 & 0.9715 \\
\hline Extended family & 16 & 15.1 & 8 & 50.0 & 8 & 50.0 & \\
\hline Scholarship & 63 & 59.4 & 35 & 55.6 & 28 & 44.4 & \\
\hline Others & 12 & 11.3 & 7 & 58.3 & 5 & 41.7 & \\
\hline \multicolumn{8}{|l|}{ Total number of family members } \\
\hline $2-4$ & 26 & 24.5 & 12 & 46.2 & 14 & 53.9 & 0.0635 \\
\hline $5-7$ & 55 & 51.9 & 36 & 65.5 & 19 & 34.6 & \\
\hline$>8$ & 25 & 23.6 & 10 & 40.0 & 15 & 60.0 & \\
\hline \multicolumn{8}{|l|}{ Birth order } \\
\hline First & 30 & 28.3 & 16 & 53.3 & 14 & 46.7 & 0.0741 \\
\hline Second & 22 & 20.8 & 12 & 54.6 & 10 & 45.5 & \\
\hline Third & 22 & 20.8 & 16 & 72.7 & 6 & 27.3 & \\
\hline Fourth & 12 & 11.3 & 8 & 66.7 & 4 & 33.3 & \\
\hline$>$ Fifth & 20 & 18.9 & 6 & 30.0 & 14 & 70.0 & \\
\hline
\end{tabular}

Statistical analysis was calculated by the $x^{2}$-test. 
Table 2 Specialty preferences among medical students by gender and ranking of choices

\begin{tabular}{|c|c|c|c|c|c|c|c|c|c|c|c|c|c|c|c|c|}
\hline \multirow{3}{*}{$\begin{array}{l}\text { Total }(n=106) \\
\text { Variable } \\
\end{array}$} & \multirow{2}{*}{\multicolumn{2}{|c|}{ Total }} & \multirow{2}{*}{\multicolumn{2}{|c|}{$\begin{array}{c}\text { First } \\
\text { Choice } \\
\end{array}$}} & \multirow{2}{*}{\multicolumn{2}{|c|}{$\begin{array}{c}\text { Female } \\
(\mathrm{n}=5854.7 \%) \\
\text { Second Choice }\end{array}$}} & \multirow{2}{*}{\multicolumn{2}{|c|}{$\begin{array}{l}\text { Third } \\
\text { Choice }\end{array}$}} & \multicolumn{6}{|c|}{ Male $(n=4845.3 \%)$} & \multirow{2}{*}{\multicolumn{2}{|c|}{$\begin{array}{l}\text { Third } \\
\text { Choice }\end{array}$}} \\
\hline & & & & & & & & & \multicolumn{2}{|c|}{ Total } & \multicolumn{2}{|c|}{$\begin{array}{c}\text { First } \\
\text { Choice }\end{array}$} & \multicolumn{2}{|c|}{$\begin{array}{l}\text { Second } \\
\text { Choice }\end{array}$} & & \\
\hline & $\mathrm{n}$ & $\%$ & $\mathrm{n}$ & $\%$ & $\mathrm{n}$ & $\%$ & $n$ & $\%$ & $n$ & $\%$ & $\mathrm{n}$ & $\%$ & $\mathrm{n}$ & $\%$ & $n$ & $\%$ \\
\hline Surgery & 33 & 56.9 & 13 & 21.4 & 9 & 15.5 & 11 & 19.0 & 33 & 68.8 & 17 & 35.4 & 9 & 18.8 & 7 & 14.6 \\
\hline Obstetrics and Gynecology & 43 & 74.1 & 21 & 36.2 & 14 & 24.4 & 8 & 13.8 & 22 & 45.8 & 3 & 6.3 & 11 & 22.9 & 8 & 16.7 \\
\hline Pediatrics & 34 & 58.6 & 12 & 20.7 & 16 & 27.6 & 6 & 10.3 & 21 & 43.8 & 2 & 4.2 & 11 & 22.9 & 8 & 16.7 \\
\hline Internal medicine & 24 & 41.4 & 6 & 10.3 & 9 & 15.5 & 9 & 15.5 & 39 & 81.3 & 17 & 35.4 & 12 & 25.0 & 10 & 20.8 \\
\hline Psychiatry & 2 & 3.4 & 0 & 0.0 & 1 & 1.7 & 1 & 1.7 & 4 & 8.3 & 2 & 4.2 & 0 & 0.0 & 2 & 4.2 \\
\hline Orthopedics & 3 & 5.2 & 0 & 0.0 & 0 & 0.0 & 3 & 5.2 & 4 & 8.3 & 0 & 0.0 & 0 & 0.0 & 4 & 8.3 \\
\hline Ophthalmology & 4 & 6.9 & 0 & 0.0 & 0 & 0.0 & 4 & 6.9 & 1 & 2.1 & 0 & 0.0 & 0 & 0.0 & 1 & 2.1 \\
\hline Dermatology & 4 & 6.9 & 0 & 0.0 & 2 & 3.5 & 2 & 3.5 & 2 & 4.2 & 1 & 2.1 & 0 & 0.0 & 1 & 2.1 \\
\hline Anesthesiology & 4 & 6.9 & 0 & 0.0 & 2 & 3.5 & 2 & 3.5 & 2 & 4.2 & 1 & 2.1 & 0 & 0.0 & 1 & 2.1 \\
\hline Radiology & 3 & 5.2 & 2 & 3.5 & 0 & 0.0 & 1 & 1.7 & 3 & 6.3 & 1 & 2.1 & 1 & 2.1 & 1 & 2.1 \\
\hline Public Health & 15 & 25.9 & 3 & 5.2 & 5 & 8.6 & 7 & 12.1 & 8 & 16.7 & 4 & 8.3 & 2 & 4.2 & 2 & 4.2 \\
\hline Family Medicine & 4 & 6.9 & 0 & 0.0 & 2 & 3.5 & 3 & 5.2 & 3 & 6.3 & 1 & 2.1 & 1 & 2.1 & 1 & 2.1 \\
\hline Basic sciences & 0 & 0.0 & 0 & 0.0 & 0 & 0.0 & 0 & 0.0 & 2 & 1.2 & 0 & 0.0 & 0 & 0.0 & 2 & 4.2 \\
\hline Ear, Nose and Throat & 0 & 0.0 & 0 & 0.0 & 0 & 0.0 & 0 & 0.0 & 0 & 0.0 & 0 & 0.0 & 0 & 0.0 & 0 & 0.0 \\
\hline
\end{tabular}

choice by both males (60.4\%) and females (65.5\%) but while only $5.2 \%$ of the females regarded it as not contributing, $20.9 \%$ of the male students stated that it did not influence their choice.

With nominal logistic regression analysis, 'lack of specialists in that area' and 'mentor emulation' were the only two factors where the differences between males and females in the issues influencing their choice of careers reached the level of statistical significance (Table 4). The 'duration of residency programme' that showed a statistically significant difference in the initial analysis did not show such a difference on logistic regression.

\section{Career counselling}

More than $90.0 \%$ of the subjects said there was no career counselling facility in the university. All respondents thought that there is a need for career counselling unit in the university. About $30.0 \%$ of female and $23.0 \%$ of male students respectively had received career counselling before in their life. These data are summarized in Table 5.

\section{Discussion}

The University of The Gambia is very young and is yet to produce its own specialists. It will have to make policies on what specialties are priorities and it is thus important to determine the factors affecting the choice of specialty by medical students in The Gambia. This will help avoid the problems of maldistribution of specialists. Surgery, Obstetrics \& Gynecology, Internal
Medicine, and Pediatrics were the most preferred specialties among medical students of The Gambia medical school in this study.

The most preferred specialty by female students was Obstetrics and Gynecology followed by Pediatrics, Surgery and Internal Medicine. For male students it was Internal Medicine followed by Surgery, Obstetrics and Gynecology and Pediatrics. These findings are similar to those reported in other studies [23-25]. Among female respondents the preferred first choice of specialty was Obstetrics and Gynecology which is similar to a study done in Jordan [25]. This however is very different from that carried out in Kenya where females chose Pediatrics as their first choice (40.0\%) followed by Surgery $(28.0 \%)$ [26]. For the males in our study, both Internal Medicine and Surgery tied for the most preferred first choice of specialty, followed by Public Health and Obstetrics and Gynecology. This is similar to the finding in Kenya where most male students chose Surgery (40.0\%) followed by Internal Medicine (15.0\%) [26].

The low rate of males choosing Obstetrics and Gynecology is different from what was seen in a study in Nigeria [27] where Obstetrics and Gynecology was their second most chosen subject. This low rate in The Gambia may be due to the country being a predominantly Muslim country.

Many studies have shown males to be more inclined towards Surgery and Internal Medicine [25] but Public Health is not that commonly preferred. The selection of 
Table 3 Factors influencing choice of specialty and their distribution among male and female students

\begin{tabular}{|c|c|c|c|c|c|c|c|c|c|c|c|c|c|c|c|c|c|c|c|c|c|}
\hline & \multirow{2}{*}{\multicolumn{2}{|c|}{ SC }} & \multirow{2}{*}{\multicolumn{2}{|c|}{ MC }} & \multicolumn{4}{|c|}{ Female $(n=5854.7 \%)$} & & & & & & & \multicolumn{4}{|c|}{ Male ( $n=48$ 45.3\%) } & & & \\
\hline & & & & & \multicolumn{2}{|c|}{$\mathrm{N}$} & \multicolumn{2}{|c|}{ MNC } & \multicolumn{2}{|c|}{ SNC } & \multicolumn{2}{|c|}{ SC } & \multicolumn{2}{|c|}{ MC } & \multicolumn{2}{|c|}{$\mathrm{N}$} & \multicolumn{2}{|c|}{ MNC } & \multicolumn{2}{|c|}{ SNC } & \multirow[b]{2}{*}{ P-value } \\
\hline & $\bar{n}$ & $\%$ & $\bar{n}$ & $\%$ & $n$ & $\%$ & $\mathrm{n}$ & $\%$ & $\bar{n}$ & $\%$ & $\bar{n}$ & $\%$ & $\bar{n}$ & $\%$ & $n$ & $\%$ & $\mathrm{n}$ & $\%$ & $\bar{n}$ & $\%$ & \\
\hline Lack of specialists in that area? & 25 & 43.1 & 13 & 22.4 & 17 & 29.3 & 1 & 1.7 & 2 & 3.5 & 22 & 45.8 & 7 & 14.6 & 9 & 18.8 & 1 & 2.1 & 9 & 18.8 & 0.5427 \\
\hline Shorter hours of practice & 4 & 6.9 & 3 & 14.6 & 22 & 47.9 & 5 & 4.2 & 24 & 27.1 & 3 & 6.3 & 7 & 14.6 & 23 & 47.9 & 2 & 4.2 & 13 & 27.1 & 0.0652 \\
\hline On-call schedule & 7 & 12.1 & 5 & 8.6 & 25 & 43.1 & 9 & 15.5 & 12 & 20.7 & 6 & 12.5 & 7 & 14.6 & 25 & 52.1 & 4 & 8.3 & 6 & 12.5 & 0.4901 \\
\hline Flexibility of specialty & 15 & 25.9 & 8 & 13.8 & 22 & 37.9 & 6 & 10.3 & 7 & 12.1 & 10 & 20.8 & 14 & 29.2 & 17 & 35.4 & 3 & 6.3 & 4 & 8.3 & 0.4642 \\
\hline Interaction with other physicians & 16 & 27.6 & 21 & 36.2 & 16 & 27.6 & 3 & 5.2 & 2 & 3.5 & 20 & 41.7 & 14 & 29.2 & 11 & 22.9 & 0 & 0.0 & 3 & 6.3 & 0.1941 \\
\hline The reputation of specialty & 24 & 41.4 & 10 & 17.2 & 22 & 37.9 & 1 & 1.7 & 1 & 1.7 & 16 & 33.3 & 11 & 22.9 & 15 & 31.3 & 1 & 2.1 & 5 & 10.4 & 0.3548 \\
\hline The duration of residency program & 8 & 13.8 & 5 & 8.6 & 29 & 50.0 & 1 & 1.7 & 15 & 25.9 & 5 & 10.4 & 15 & 31.3 & 22 & 45.8 & 3 & 6.3 & 4 & 8.3 & 0.4642 \\
\hline Work pressure & 10 & 17.2 & 11 & 19.0 & 22 & 37.9 & 4 & 6.9 & 11 & 19.0 & 5 & 10.4 & 9 & 18.8 & 20 & 41.7 & 6 & 12.5 & 8 & 16.7 & 0.7525 \\
\hline Interest in research & 31 & 53.5 & 9 & 15.5 & 12 & 20.7 & 4 & 6.9 & 2 & 3.5 & 22 & 45.8 & 14 & 29.2 & 10 & 20.8 & 0 & 0.0 & 2 & 4.2 & 0.8909 \\
\hline $\begin{array}{l}\text { Interest in long term relations } \\
\text { with patients }\end{array}$ & 23 & 39.7 & 13 & 22.4 & 18 & 31.0 & 1 & 1.7 & 3 & 5.2 & 11 & 22.9 & 19 & 39.6 & 15 & 31.3 & 0 & 0.0 & 3 & 6.3 & 0.3531 \\
\hline Physician patient interaction & 31 & 53.5 & 10 & 17.2 & 11 & 19.0 & 1 & 1.7 & 5 & 8.6 & 16 & 33.3 & 19 & 39.6 & 9 & 18.8 & 0 & 0.0 & 4 & 8.3 & 0.2233 \\
\hline Diversity of patients & 21 & 36.2 & 15 & 25.9 & 16 & 27.6 & 4 & 6.9 & 2 & 3.5 & 13 & 27.1 & 16 & 33.3 & 13 & 27.1 & 3 & 6.3 & 3 & 6.3 & 0.4854 \\
\hline Anticipated income & 11 & 19.0 & 11 & 19.0 & 27 & 46.6 & 5 & 8.6 & 4 & 6.9 & 8 & 16.7 & 12 & 25.0 & 18 & 37.5 & 1 & 2.1 & 9 & 18.8 & 0.1979 \\
\hline Focus on community health & 24 & 41.4 & 12 & 20.7 & 15 & 25.9 & 2 & 3.5 & 5 & 8.6 & 18 & 38.3 & 14 & 29.8 & 11 & 23.4 & 2 & 4.2 & 2 & 4.2 & 0.8992 \\
\hline Focus on urgent care & 38 & 65.5 & 6 & 10.3 & 12 & 20.7 & 0 & 0.0 & 2 & 3.5 & 24 & 50.0 & 12 & 25.0 & 8 & 16.7 & 0 & 0.0 & 4 & 8.3 & 0.1884 \\
\hline The curriculum & 19 & 32.8 & 15 & 25.9 & 22 & 37.9 & 0 & 0.0 & 2 & 3.5 & 12 & 25.0 & 14 & 29.2 & 17 & 35.4 & 1 & 2.1 & 4 & 8.3 & 0.3433 \\
\hline $\begin{array}{l}\text { The intellectual content } \\
\text { of specialty }\end{array}$ & 33 & 56.9 & 7 & 12.1 & 15 & 25.9 & 0 & 0.0 & 3 & 5.2 & 29 & 60.4 & 8 & 16.7 & 9 & 18.8 & 0 & 0.0 & 2 & 4.2 & 0.5619 \\
\hline That you are likely to stay in the city & 12 & 20.7 & 3 & 5.2 & 26 & 44.8 & 4 & 6.9 & 13 & 22.4 & 5 & 10.4 & 7 & 15.6 & 22 & 45.8 & 2 & 4.2 & 12 & 25.0 & 0.7238 \\
\hline The individual's competencies & 28 & 48.3 & 9 & 15.5 & 17 & 29.3 & 2 & 3.5 & 2 & 3.5 & 24 & 50.0 & 9 & 18.8 & 12 & 25.0 & 1 & 2.1 & 2 & 4.2 & 0.7394 \\
\hline Mentor emulation & 14 & 24.1 & 10 & 17.2 & 26 & 44.8 & 3 & 5.2 & 5 & 8.6 & 17 & 35.4 & 14 & 29.2 & 13 & 27.1 & 2 & 4.2 & 2 & 4.2 & 0.0383 \\
\hline Advice from faculty members & 9 & 15.5 & 7 & 12.1 & 26 & 44.8 & 5 & 8.6 & 11 & 19.0 & 5 & 10.4 & 10 & 20.8 & 19 & 39.6 & 3 & 6.3 & 11 & 22.9 & 0.6738 \\
\hline Advice from friends & 6 & 10.3 & 9 & 15.5 & 25 & 43.1 & 2 & 3.5 & 16 & 27.6 & 6 & 12.5 & 8 & 16.7 & 18 & 37.5 & 5 & 10.4 & 11 & 22.9 & 0.6467 \\
\hline Advice from parents & 14 & 24.1 & 10 & 17.2 & 20 & 34.5 & 3 & 5.2 & 11 & 19.0 & 6 & 12.5 & 13 & 27.1 & 18 & 37.5 & 2 & 4.2 & 9 & 18.8 & 0.5279 \\
\hline Advice from practicing physicians & 15 & 25.9 & 12 & 20.7 & 23 & 39.7 & 1 & 1.7 & 7 & 12.1 & 12 & 25.0 & 10 & 20.8 & 17 & 35.4 & 2 & 4.2 & 7 & 14.6 & 0.9368 \\
\hline
\end{tabular}


Table 4 Univariate logistic regression to isolate gender differences in factors influencing career choice

\begin{tabular}{|c|c|c|c|c|}
\hline & \multirow[b]{3}{*}{ OR } & \multicolumn{3}{|c|}{ Female vs Male } \\
\hline & & \multicolumn{3}{|c|}{ Univariate } \\
\hline & & $95 \% \mathrm{Cl}$ & & $\overline{p \text {-value }}$ \\
\hline \multicolumn{5}{|c|}{ 'Lack of specialists in that area' } \\
\hline Neutral & 1.0 & & & \\
\hline Contributory & 0.7 & $0.3-$ & 1.8 & 0.4465 \\
\hline Not Contributory & 0.2 & $0.0-$ & 0.7 & $0.0178^{*}$ \\
\hline \multicolumn{5}{|l|}{ 'Mentor emulation' } \\
\hline Neutral & 1.0 & & & \\
\hline Contributory & 0.4 & $0.2-$ & 0.9 & $0.0292^{*}$ \\
\hline Not Contributory & 1.0 & $0.3-$ & 4.3 & 1.0000 \\
\hline \multicolumn{5}{|c|}{ 'Duration of residency' } \\
\hline Neutral & 1.0 & & & \\
\hline Contributory & 0.5 & $0.2-$ & 1.2 & 0.1201 \\
\hline Not Contributory & 2.0 & $0.7-$ & 6.4 & 0.2051 \\
\hline
\end{tabular}

Public Health as third choice by our male students is peculiar. This might be because The Gambia had a School of Public Health many decades before the establishment of the medical school and Public Health officers man several health projects in the Ministry of Health. Medical students may be hoping to take over these projects upon graduation, being better qualified than the present Diploma in Public Health holders.

Unlike in Jordan where Orthopedics was the third most preferred specialty, none of the male respondents in this study chose it as a first choice. This is of major concern as The Gambia needs urgent human resources in the area of Accidents and Traumatology and students need to be encouraged to consider this.

Similar to a study done in Jordan no male chose Anesthesia as a first choice but was considered by $4.2 \%$ of females. This can be attributed to the number of nurse anesthetists employed at university hospitals [25]. The teaching hospital in The Gambia has a Diploma programme for nurse anesthetists. Medical students may be reluctant to compete with nurses and thus will explore other fields instead.

The low rate of choice of Basic Medical Sciences is noteworthy as no female considered it and even the two males who did, chose it as their third choice. Previous studies have shown that whenever a specialty is not even considered among the first three choices then it is very unlikely that students would consider it later for specialization $[4,8,28]$. This is of concern because currently, nearly all the Basic Medical Science lecturers and practitioners at The Gambia Medical School are expatriates. It is necessary to identify the factors that discourage students from this area and rectify them in order to have the required manpower for this field.

Family Medicine was found to be one of the least popular specialties preferred, which is consistent with the findings of other studies [4,29,30]. Medical students in The Gambia must be encouraged to take up Family Medicine so that our health care system can be involved more in health promotion activities, as soon as the minimum required number of specialists to run the medical school has been attained. Many researchers have tried to determine the factors that influence the choice of specialty by medical students $[9,10,31]$. Both personal and academic (preclinical and clinical) experiences are important in shaping students' perceptions of specialties and their personal choices [9]. Mentoring, a process of giving advice, imparting knowledge or teaching psychomotor skills over a period of time to a junior apprentice by a senior colleague is very important in medical practice, with the former wishing to be like the latter. Some authors have indeed shown 'mentor emulation or positive interaction' to be very influential in career choice amongst medical students [9,32].

We have found 'mentor emulation' to have been considered significantly differently between males and females, being more influential amongst the former. 'Mentor emulation' has been found to be highly rated in Surgery [25] and this is the specialty chosen by majority of the male students. 'Lack of specialists in that specialty' was highly rated as being contributory to their choice by both sexes. This is important in The Gambia as the medical school has just started training doctors and there are no indigenous specialists in most of the specialties. Many students are motivated to be the first specialists in their areas of choice. A much higher proportion of the male students than the females, however, did not consider this to be a factor contributing to their choice. This may also be related to the fact that

Table 5 Distribution of responses on the need for career counseling among students

\begin{tabular}{|c|c|c|c|c|c|c|c|c|}
\hline & \multicolumn{4}{|c|}{ Female $(n=5854.7 \%)$} & \multicolumn{4}{|c|}{ Male $(n=48,45.3 \%)$} \\
\hline & \multicolumn{2}{|c|}{ Yes } & \multicolumn{2}{|c|}{ No } & \multicolumn{2}{|c|}{ Yes } & \multicolumn{2}{|c|}{ No } \\
\hline & $\mathrm{n}$ & $\%$ & $\mathrm{n}$ & $\%$ & $\mathrm{n}$ & $\%$ & $\mathrm{n}$ & $\%$ \\
\hline Do you have career counseling unit in your university? & 2 & 3.5 & 56 & 97 & 3 & 6.3 & 45 & 94 \\
\hline Do you think there is a need for career counseling unit in your Medical school? & 58 & 100.0 & 0 & 0.0 & 48 & 100.0 & 0 & 0.0 \\
\hline Have you ever received career counseling? & 17 & 29.3 & 41 & 71 & 11 & 22.9 & 37 & 77 \\
\hline
\end{tabular}


Surgery, the choice of a large number of the male students is already well-represented among the specialists in the institution.

It was surprising to find in our study that a higher proportion of male students found 'duration of residency program' a contributory factor to their choice, compared to their female counterparts. This deviates from the expectation that female doctors might wish to finish with residency training more quickly so as to have more time for their families.

The findings of a study in Turkey revealed that the most important reasons for the choice of specialty were "better financial opportunities" and "prestige", followed by "personal development", "more benefits for the patient", and "wish to work in an urban area". The situation is quite different from the results of our study as both sexes did not rate 'expected income' or these other factors high among the factors contributing to their choice.

The most important factors that affected choice of specialty among female respondents were 'focus on urgent care' followed by "the intellectual content of the specialty" and then "interest in research". Because most female respondents chose Obstetrics and Gynaecology as their first specialty, it is reasonable that "focus on urgent care" is rated the most influential factor for their choice of specialty. Female respondents rated "interest in research" as an influential factor more than their male counterparts.

All the students in our study said that there was no career counselling facility in the medical school. Only one quarter $(25.0 \%)$ of both sexes had received career counselling before. This is not ideal as students are left on their own without guidance including in the choice of their intended specialties. This may lead to a lot of trial and error and may cause delay. Career guidance ought to be offered early, based on evidence and tailored to the characteristics and needs of the individual. Young doctors should be able to recognise the exciting possibilities open to them and base their decisions on positive choice rather than an increasingly demoralising process of elimination [19]. All students agreed that there is need for career counselling in the medical school. But the method of career counselling most appropriate would have to be determined in another study as there are different methods and tools [19].

\section{Conclusions}

This study was undertaken to determine the career preferences of medical students at the University of The Gambia Medical School and the factors influencing these choices. It was also to determine their need for career counselling. The most common specialty chosen by female students was Obstetrics and Gynaecology probably because of the predominant religion in the country while the most influential factor was 'focus on urgent care'. Males' predominant choices of specialty consisted of Internal Medicine and Surgery. 'The intellectual content of the specialty' was their most influencing factor. The Basic Medical Sciences were not the first or second choice of any student. No male or female chose ENT in any of their three allowed choices.

Less than one third of all students had ever received career counseling and all students regarded career counseling as a necessity. It is recommended that career counseling units be set up in the medical school and students be counseled early in order to assist them choose appropriate careers and also prevent maldistribution of doctors among the specialties. A study to identify the best method of counseling students in this medical school is hereby suggested.

The Government of The Gambia should encourage students to specialize in less preferred areas that are essential in the short term.

This study has limitations as it did not determine the point in their schooling that medical students actually make their decisions in order to know the most appropriate stage to introduce career counselling. The response rate was also not very large. More analysis could have been done with the demographic information but gender was the main outcome measure analyzed.

\section{Competing interests}

We hereby declare that MB submitted a dissertation based on findings from this study in partial fulfillment of the requirement for the award of the Master of Science degree in Biomedical Education of the Faculty of Clinical Sciences, College of Medicine, University of Ibadan, Nigeria in 2011.

\section{Authors' contributions}

MB conceptualized the study, drafted the proposal, collected and analysed data, and wrote the article. AAO revised the proposal, the analysed data, took part in the write-up and is the correspondence author. ON was involved in the conceptualization, data analysis and write-up. BJ assisted with data collection and analysis. AOO revised the data analysis and assisted in the write-up. All authors read and approved the final manuscript.

\section{Acknowledgements}

The support of the African, Caribbean and Pacific Group of States (ACP Secretariat) at the European Union through the ACP-EU Cooperation Programme in Higher Education (EDULINK), which provided a grant [No. 9 ACP RPR 12 \# 31] to establish the Master of Science in Biomedical Education programme at the University of Ibadan, is gratefully acknowledged. MB was one of the sponsored pioneer students and the data in this paper were part of his dissertation.

We thank Dr. Kebba Bojang and the staff and students of The Gambia Medical School.

\section{Author details}

${ }^{1}$ Department of Obstetrics and Gynaecology, KorleBu University Teaching Hospital, Accra, Ghana. '2Department of Obstetrics and Gynaecology, College of Medicine, University of Ibadan, Ibadan, Nigeria. ${ }^{3}$ Department of Medicine, School of Medicine and Allied Health Sciences, University of The Gambia, Banjul, The Gambia. ${ }^{4}$ Department of Medicine, Royal Victoria Teaching Hospital, Banjul, The Gambia.

Received: 24 January 2012 Accepted: 1 August 2012 Published: 8 August 2012 


\section{References}

1. Linzer M, Slavin T, Mutha S, Takayama Jl, Branda L, VanEyck S, McMurray JE, Rabinowitz HK: Admission, recruitment, and retention: finding and keeping the generalist-oriented student. SGIM task force on career choice in primary care and internal medicine. J Gen Intern Med 1994 4(Suppl 1):S14-S23.

2. Apker J, Eggly S: Communicating professional identity in medical socialization: Considering the ideological discourse of morning report. Qual Health Res 2004, 14(3):411-429.

3. Gorenflo DW, Ruffin MT 4th, Sheets KJ: A multivariate model for specialty preference by medical students. J Fam Pract 1994, 39(6):570-576.

4. Wright B, Scott I, Woloschuk W, Brenneis F, Bradley J: Career choice of new medical students at three Canadian universities: family medicine versus specialty medicine. CMAJ 2004, 170(13):1920-1924.

5. McManus IC, Lefford F, Furnham AF, Shahidi S, Pincus T: Career preference and personality differences in medical school applicants. Psychol Health Med 1996, 1:235-248.

6. Hutt R, Parsons D, Pearson R: The timing of and reasons for doctors' career decisions. Health Trends 1981, 13:17-20.

7. Zeldow PB, Preston RC, Daugherty SR: The decision to enter a medical specialty: timing and stability. Med Educ 1992, 26(4):327-332.

8. Colwill JM: Where have all the primary care applicants gone? N Engl J Med 1992, 326:387-393.

9. Saigal P, Takemura Y, Nishiue T, Fetters MD: Factors considered by medical students when formulating their specialty preferences in Japan: findings from a qualitative study. BMC Med Educ 2007, 7:31.

10. Pawelczyk A, Pawelczyk T, Bielecki J: The effect of some factors on medical student specialty choice of non-primary care-a synthesis of the literature. Pol Merkur Lekarki 2007, 22:575-579.

11. Paris J, Frank H: Psychological determinants of a medical career. Can J Psychiatry 1983, 28:354-357.

12. Crimlisk HL, McManus IC: The effect of personal illness experience on career preference in medical students. Med Educ 1987, 21(6):464-467.

13. Weil PA, Schleiter MA: National Study of Internal Medicine Manpower: VI. Factors Predicting Preferences of Residents for Careers in Primary Care or Subspecialty Care and Clinical Practice or Academic Medicine. Ann Intern Med 1981, 94(5):691-703.

14. Dorsey ER, Jarjoura D, Rutecki GW: The influence of controllable lifestyle and sex on the specialty choices of graduating U.S. medical students,1996-2003. Acad Med 2005, 80(9):791-796.

15. Feifel D, Moutier C, Swerdlow N: Attitudes toward Psychiatry as a prospective career among students entering medical school. Am J Psychiatry 1999, 156:1397-1402.

16. Reeve PE: Personality characteristics of a sample of anaesthetists. Anaesthesia 1980, 35(6):559-568.

17. Parkhouse J, Ellin DJ: Anaesthetics: career choices and experiences. Med Educ 1990, 24(1):52-67.

18. Lambert T, Goldacre M, Parkhouse J: Doctors who qualified in the UK between 1974 and 1993: age, gender, nationality, marital status and family formation. Med Educ 1998, 32:533-537.

19. Colin S, Anthea L: Career counseling. In Postgraduate medical education and training: a guide for primary and secondary care. Edited by Hastie A, Hastie I, Jackson N. Oxford: Radcliffe Publishing Ltd; 2005:73-80. Chapter 7.

20. Schwartz B: The tyranny of choice. Sci Am 2004, 290(4):70-75.

21. Edwards C, Lambert TW, Goldacre MJ, Parkhouse J: Early medical career choices and eventual careers. Med Educ 1997, 31(4):237-242.

22. Census classified index of occupations. Industry and Occupation. www.census gov/hhes/www/ioindex/ioindex02/cens02. Cited 01.06.2012.

23. Mariolis A, Mihas C, Alevizos A, Gizlis V, Mariolis T, Marayiannis K, Tountas Y Stefanadis C, Philalithis A, Creatsas G: General Practice as a career choice among undergraduate medical students in Greece. BMC Med Educ 2007, 7:15.

24. Avgerinos ED, Msaouel P, Koussidis GA, Keramaris NC, Bessas Z, Gourgoulianis K: Greek medical students' career choices indicate strong tendency towards specialization and training abroad. Health Policy 2006, 79:101-106.

25. Yousef K, Dema A-Z, Zouhair A, Ahmad A, Mohammad K, Samar B, Khalid El S, Mousa $O$ : Factors affecting medical students in formulating their specialty preferences in Jordan. BMC Med Educ 2008, 8:32.

26. Maseghe Mwachaka P, Thuo Mbugua E: Specialty preferences among medical students in a Kenyan university. Pan Afr Med J 2010, 5:18.
27. Makama JG, Ameh EA: Does General Surgery clerkship make a future career in Surgery more appealing to medical students? Afr Health Sci 2010, 10(3):292-296.

28. Rabinowitz HK: The role of the medical school admissions process in the outcome of generalists physicians. Acad Med 1999, 74:S39-S44.

29. Pugno PA, McPherson DS, Schmittling GT, Kahn NB Jr: Results of the 2001 national resident matching program: family practice. Fam Med 2001, 33(8):594-601.

30. Senf JH, Campos-Outcalt D, Kutob R: Factors related to the choice of Family Medicine: a reassessment and literature review. J Am Board Fam Pract 2003, 16(6):502-512.

31. Millan LR, Azevedo RS, Rossi E, De Marco OL, Millan MP, de Arruda PC: What is behind a student's choice for becoming a doctor? Clinics 2005, 60:143-150

32. Zarkovic A, Child S, Naden G: Career choices of New Zealand junior doctors. N Z Med J 2006, 119(1229):U1851.

doi:10.1186/1472-6920-12-72

Cite this article as: Bittaye et al:: Medical students' choices of specialty in The Gambia: the need for career counseling. BMC Medical Education 2012 $12: 72$.

\section{Submit your next manuscript to BioMed Central and take full advantage of:}

- Convenient online submission

- Thorough peer review

- No space constraints or color figure charges

- Immediate publication on acceptance

- Inclusion in PubMed, CAS, Scopus and Google Scholar

- Research which is freely available for redistribution

Submit your manuscript at www.biomedcentral.com/submit
C BioMed Central 